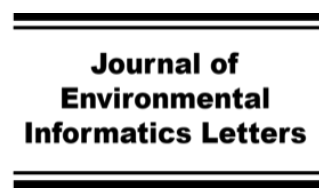

www.iseis.org/jeil

\title{
A Review of Numerical Models for Oil Penetration, Retention, and Attenuation on Shorelines
}

\author{
E. Taylor ${ }^{1}{ }^{*}$, E. H. Owens ${ }^{2}$, K. Lee ${ }^{3}$, C. J. An ${ }^{4}$, and Z. Chen ${ }^{4}$ \\ ${ }^{1}$ Polaris Applied Sciences, Inc., 755 Winslow Way East \#302, Bainbridge Island, WA 98110, USA \\ ${ }^{2}$ OCC Ltd., 755 Winslow Way East \#205, Bainbridge Island, WA 98110, USA \\ ${ }^{3}$ Ecosystem Science, Fisheries and Oceans Canada, Ottawa, ON K1A OE6, Canada \\ ${ }^{4}$ Department of Building, Civil and Environmental Engineering, Concordia University, Montreal, Quebec H3G 1M8, Canada
}

Received 16 October 2020; revised 08 December 2020; accepted 26 December 2020; published online 04 April 2021

\begin{abstract}
Oil spills that reach shorelines greatly increase risks to coastal resources. Understanding how long oil is likely to remain on a shoreline is important in deciding response priorities, areas to clean, and the degree of intervention recommended. Wave action, tides, and currents can relocate oil laterally along the beach, cause oil to penetrate vertically into the sediments, and remove oil from the shoreline. Physico-chemical processes transfer some hydrocarbons to the atmosphere and to the adjacent water column resulting in diminished oil on the shoreline. Oil dispersion, through formation of oil-particulate aggregates, and microbial degradation processes can break down a large fraction of the residual oil remaining on and within shorelines. A comprehensive review of the scientific literature reveals that although there are many models that describe and predict oil transport, behavior, and fate in the sea, few numerical models have been developed for oil stranded on shorelines. Canada's Multi-Partner Research Initiative Program aims to develop a model-based "Decision Support Tool" that can predict the rates of oil loss that can be achieved from natural attenuation processes and the application of active spill response strategies. This model is built on the understanding of factors controlling: penetration, holding capacity, retention, and the residual capacity (persistence) of oil stranded on shorelines derived from the results of case histories, laboratory, meso-scale tests and field trials. Output from the model is intended to support spill response decision-making by allowing spill responders and the public to visualize the results achieved by natural attenuation versus remedial strategies.
\end{abstract}

Keywords: oiled shorelines, modeling, oil removal, oil translocation, oil attenuation

\section{Introduction}

Oil in the marine environment originates from numerous sources, primarily through natural seeps (46\%), consumer use (runoff, recreational and commercial vessels, 37\%), and from accidental discharges during transportation of petroleum products (12\%) (NRC, 2003). Although the number of major spills has decreased over the past decades, the instances in which these incidents do occur represent challenges and threats to environmental and human resources, particularly where affecting shorelines. Oil spilled at sea and on coasts enters a dynamic environment in which the oil moves rapidly between the very different physical and ecological systems of the shoreline and adjacent waters. There are three primary natural oil translocation pathways of importance for shorelines following an oil spill: 1) oil to shorelines, 2) shoreline oil to nearshore waters, and 3) oil movement within the shoreline. Understanding these pathways and the processes by which oil is translocated off a shoreline is critical in deciding how much intervention or cleanup is

${ }^{*}$ Corresponding author. Tel.: +1 2067800860 .

E-mail address: ETaylor@PolarisAppliedSciences.com (E. Taylor).

ISSN: 2663-6859 print/2663-6867 online

(C) 2021 ISEIS All rights reserved. doi:10.3808/jeil.202100051 appropriate to promote oil translocation processes and natural attenuation, and thus reduce environmental risk and accelerate recovery of the environment.

The Canadian federal government has launched a series of research and support programs under the Oceans Protection Plan (OPP) to enhance the capability and resources for oil spill response. The OPP's Multi-Partner Research Initiative (MPRI) brings together a network of scientists from industry, academia and government to address five key research areas in oil spill response, one of which encompasses oil translocation. A primary objective of the oil translocation theme is to better understand the natural attenuation of oil stranded on the marine shorelines of Canada in the context of oil exposure risk and shoreline treatment options. One of the oil translocation project goals is to develop a shoreline response program decision tool to facilitate our understanding of the trade-offs of shoreline treatment relative to natural attenuation. Such a tool requires simulation modeling to analyze the effectiveness of natural attenuation and the available intervention techniques under a range of environmental conditions expected to be encountered.

Compared to other aspects of spill response, such as chemical dispersant use, herding technology, or controlled burns on water, very little effort has been focused on the processes of stranded oil translocation, which is critical to understanding 
their significance in the natural attenuation of oil from shorelines for different geographical locations and oil types. To address this knowledge gap, the first phase of the oil translocation study program focused on the review of existing scientific literature on natural attenuation processes and pathways and the application of that data in models related to oil penetration and retention on sediment shorelines.

\subsection{Background}

Natural cleaning processes of oil off shorelines include physical transport and washing associated with waves, buoyancy and re-floatation from tides, evaporation of light end compounds, dispersion through oil-particle interactions, and gradual biodegradation of oil. The contribution of each pathway or process is generally understood; however, very few studies have been completed that focus on the combination of these processes over a wide range of environmental conditions, shoreline types, and oils.

The behavior and fate of oil on freshwater and marine shorelines has been less well studied and is less understood than oil in the sea. There exist many models that describe and attempt to predict oil transport, behavior, and fate in the marine environment (NRC, 2003), to the extent that a review conducted 25 years ago cited more than 50 composite oil-slick models at that time (ASCE, 1996). By comparison, only a handful of numerical models have ever been developed for oil on shorelines.

Assessing the risks associated with the exposure of coastal resources or human activities to stranded oil is a major component of response decisions following an oil spill to the marine environment. The duration of the exposure, and therefore the level of risk, is directly related to the retention or persistence of the stranded oil, which is a function of the specific properties of the oil and a series of interactive weathering or degradation processes (Figure 1). American Petroleum Institute (API) (2014) noted that the processes contributing to natural attenuation of oil from substrates include biodegradation, biological stabilization, chemical oxidation or reduction, sorption to soil or sediments, volatilization, disperseon, advection by waves to the open water, and dilution. Some of the processes, such as evaporation (volatilization) and spreading, are significant and rapid during the initial period of weathering after a spill whereas others, such as photo-oxidation and biodegradetion, are longer term processes in the ultimate fate of oil (IMO, 2005). The net result of the combination of these weathering processes is the transformation and natural attenuation of the stranded oil.

Importantly, there are only three ways in which oil is reduced to simple compounds and removed from the environment:

- biodegradation,

- $\quad$ photo-oxidation, and

- thermal oxidation (burning or combustion).

All three removal processes are associated primarily with oxygen although oil biodegradation can occur in anaerobic environments (e.g., Ghattas et al., 2017). All other weathering processes (e.g., dispersion, dissolution, emulsification, evaporation, sedimentation, spreading) result in changes to the chemical and physical properties of stranded oil (adhesiveness, com- position, density, specific gravity, surface tension, viscosity), which in turn affect the pathways and rates that stranded oil is transferred from one location, or medium, to another ("oil translocation") (Table 1).

Natural attenuation can lower the risk of exposure to stranded oil by diluting and transforming potentially harmful compounds of the oil. The half-life of oil stranded on a shoreline can vary from as little as a few hours for very light products, such as gasoline, to many years for oil sequestered in sediments or that forms an asphalt pavement (Owens et al., 1986, 2008; Prince et al., 2017). The ability to understand the rates of attenuation and the final fate of stranded oil is a critical input during the decision process to determine response priorities and operational treatment options and targets.

\subsection{Application in Decision-Making for Treatment}

The shoreline response decision process to date has typically relied on hard copy or electronic technical manuals and guides to provide information on the applicability and effecttiveness of treatment options [e.g., CEDRE (2013), NOAA (2013), IPIECA-IOGP (2015), ECCC (2016)]. Although numerical models have been applied extensively during spill response exercises and following actual incidents to estimate or predict the trajectory of the oil on water and in the water column (e.g., DeDominicis et al., 2013; Samaras et al., 2014), they have not been developed and utilized to estimate the persistence of oil stranded on shorelines. This may be due to the complexity of interrelated processes and a limitation in the understanding of the concepts and terminology controlling the transport and fate of oil stranded on shorelines by the majority of those in the spill response community. To address this issue, one of the objectives of the MPRI program is to create a dynamic, interactive, multilayered, seasonal, and geographic-based model for shoreline oil spill response decision analyses. The MPRI model is intended to form the basis of a decision support tool for environmental resource managers, spill responders, and the public that illustrates the fate and behavior of oil stranded on shorelines and the ramifications, and consequences, of shoreline treatment options without the need to understand technical materials (Owens et al., 2021).

\section{Model Approaches}

Risk assessments use numerical models or judgements based on past experiences (insight) to estimate the persistence of stranded oil and the exposure of coastal resources and human activeties. Laboratory-scale experiments and field studies have been conducted to generate data to better understand the key factors that drive the rates of natural oil attenuation. Conceptual and numerical models have been developed to characterize and define oil transfer between the shoreline and adjacent water and to estimate the persistence of stranded oil (Pope et al., 2013). The quality or accuracy of a predictive numerical model, in this case related to oil retention on shorelines, depends on: (a) understanding those processes that affect the stranded oil and (b) the availability of good quality data for the model inputs. 


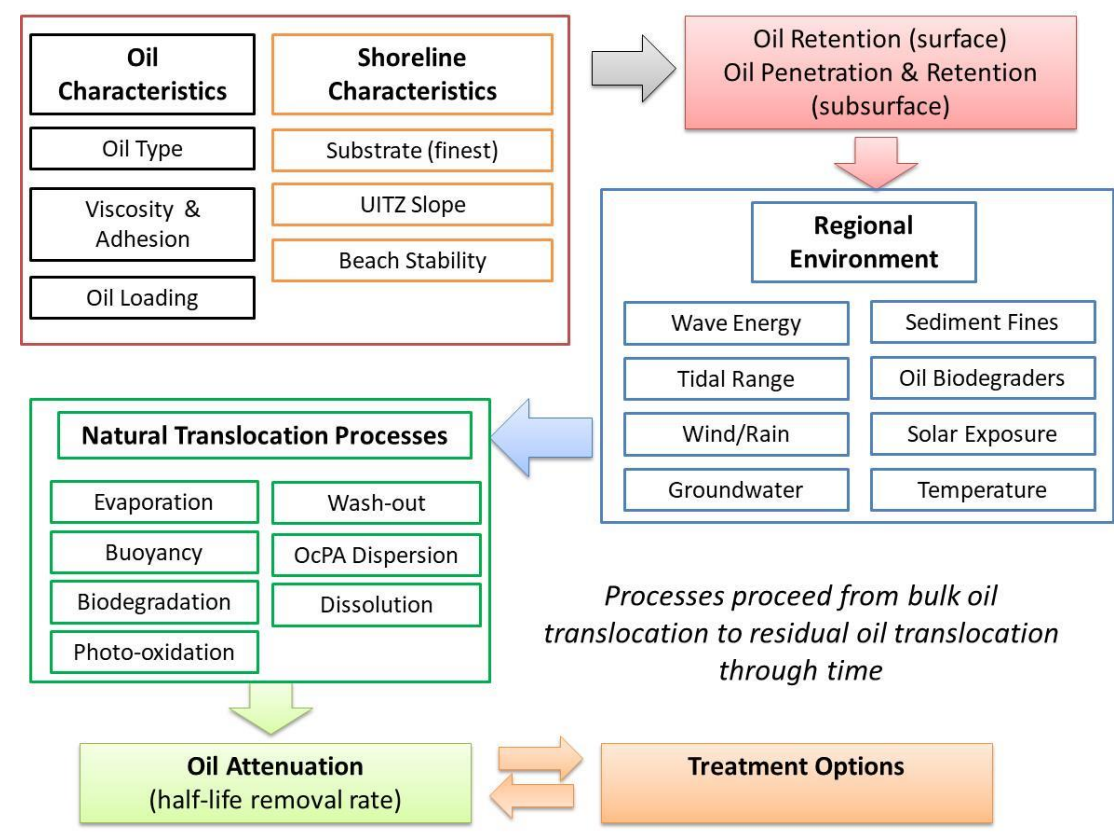

Figure 1. Factors associated with shoreline oil translocation.

Table 1. Natural Oil Translocation Pathways from Shorelines (adapted from Owens et al., 2021).

\begin{tabular}{|c|c|c|}
\hline Oil Weathering Process & Translocation Pathway & Features \\
\hline Evaporation & Shoreline - Air & $\begin{array}{l}\text { Volatilization and dispersion as small compounds vaporize from a liquid to a } \\
\text { gas phase; airborne particles may be photo-oxidized or deposited on land or } \\
\text { sea by precipitation. }\end{array}$ \\
\hline $\begin{array}{l}\text { Break Down by } \\
\text { Waves/Currents }\end{array}$ & Shoreline - Water & $\begin{array}{l}\text { Stranded oil is broken down, eroded, disintegrated, flushed, and dispersed by } \\
\text { wave and/or current action to an adjacent water body. }\end{array}$ \\
\hline Buoyancy Partitioning & Shoreline - Water & $\begin{array}{l}\text { Physical partitioning as free or adhered oil on a shoreline is released, } \\
\text { remobilized, floated, rinsed, and dispersed to a water body by water motion. } \\
\text { May involve but does not require wave or current energy. }\end{array}$ \\
\hline Aggregation & Shoreline - Water & $\begin{array}{l}\text { Formation of a buoyant oil-water-fine sediment emulsion (OcPA: Oil- } \\
\text { colloidal Particle Aggregation) in the presence of fine sediments }(<0.05 \mathrm{~mm}) \\
\text { and water. Oil is dispersed by water motion; does not require physical wave or } \\
\text { current energy. }\end{array}$ \\
\hline Biodegradation & In Situ & Direct degradation of exposed oil surfaces that does not require physical \\
\hline Photo-Oxidation & In Situ & $\begin{array}{l}\text { transfer from one environment to another. In addition, both transformation } \\
\text { processes may take place during translocation (partitioning and transport). }\end{array}$ \\
\hline
\end{tabular}

\subsection{Inputs and Outputs}

In order to model oil removal off shorelines there are numerous variables to consider (Owens et al., 2008; Pope et al., 2013; Boufadel et al., 2019). Inputs to the modeling process include oil and shoreline characteristics and prevailing environmental conditions (waves, tides, weather) (Table 2). Key oil properties to consider are viscosity and adhesion to substrate (influenced by emulsion formation and the weathering of oil) prior to, and after, stranding on the shoreline. Important shoreline characteristics include sediment texture, beach slope and width, wave energy, tidal range (spring/neap) and frequency (diurnal/semidiurnal), and groundwater conditions. Dynamic conditions occur along shorelines that can temporarily but significantly modify conditions affecting oil persistence such as storm events and beach build-up or erosion.

\subsection{Loading, Penetration, and Holding Capacity}

Oil initially begins to coat surface substrates once it reaches the shoreline. The degree to which oil adheres to the sediment is a function of oil adhesion and the substrate surface itself, particularly if wet and covered with a biofilm (Lee et al., 2015). The oil can penetrate into the sediment subsurface if sufficient volume reaches the shoreline to fill the surface void spaces between sediment particles. The extent to which oil penetration occurs is a function of oil loading, time for infiltration, beach saturation, sediment grain size, oil viscosity, and oil adhesion (Humphrey et al., 1993; Harper et al., 2015). Both the adhesion and wetting properties of oils are greatly influenced by the proportion of asphaltenes that make up the oil (fresh or weathered) (Lee et al., 2015). Terminology typically used in studies to describe these processes varies but is generally aligned between 
Table 2. Factors that Affect the Persistence of Stranded Oil (Adapted from Owens et al., 2008)

\begin{tabular}{|c|c|c|}
\hline Parameter & Factors That Lead to Lower Persistence & Factors That Lead to Higher Persistence \\
\hline Oil Character & $\begin{array}{l}\text { Light or non-persistent oils (e.g., high API gravity } \\
\text { crudes, distillates). }\end{array}$ & $\begin{array}{l}\text { Heavy or weathered oils, stable emulsions, and } \\
\text { sticky (high adhesion) oils. }\end{array}$ \\
\hline Oil Amount & $\begin{array}{l}\text { Small amounts or concentrations at any one } \\
\text { location. }\end{array}$ & $\begin{array}{l}\text { Large amounts or concentrations at any one } \\
\text { location. }\end{array}$ \\
\hline Shoreline Type & Impermeable bedrock or fine-grained sediments. & $\begin{array}{l}\text { Coarse sediments underlain by fine sediment or } \\
\text { bedrock. }\end{array}$ \\
\hline $\begin{array}{l}\text { Location with Respect to Tidal } \\
\text { Water Levels }\end{array}$ & $\begin{array}{l}\text { Deposition within the tidal zone and zone of } \\
\text { normal wave action. }\end{array}$ & $\begin{array}{l}\text { Deposition above the tidal zone and the zone of } \\
\text { normal wave action. }\end{array}$ \\
\hline $\begin{array}{l}\text { Location with Respect to Mobile } \\
\text { Sediments }\end{array}$ & $\begin{array}{l}\text { Deposition within the zone of normal sediment } \\
\text { reworking and redistribution. }\end{array}$ & $\begin{array}{l}\text { Penetration or burial to a depth below the layer of } \\
\text { mobile sediment and sediment reworking. }\end{array}$ \\
\hline Interference by Humans & $\begin{array}{l}\text { Treatment or cleaning by response operations. } \\
\text { Coastal engineering works that result in shoreline } \\
\text { retreat; e.g., beach mining. }\end{array}$ & $\begin{array}{l}\text { Coastal engineering works that result in shoreline } \\
\text { stabilization or progradation; beach nourishment; } \\
\text { and/or oil burial. }\end{array}$ \\
\hline Interference by Nature & $\begin{array}{l}\text { Dynamic or eroding shores. Earth } \\
\text { movements/water level changes that lower the } \\
\text { elevation of the shore zone. }\end{array}$ & $\begin{array}{l}\text { Stable or prograding shorelines. Earth } \\
\text { movements/water level changes that raise the } \\
\text { elevation of the shore zone. }\end{array}$ \\
\hline
\end{tabular}

Table 3. Terminology Used in Relation to Oil Processes on and within Shorelines

\begin{tabular}{|c|c|c|}
\hline Term & Meaning & Units Used \\
\hline \multicolumn{3}{|l|}{ Input } \\
\hline Adhesion (Or Stickiness) & $\begin{array}{l}\text { The tendency of dissimilar particles or surfaces to cling to one another } \\
\text { (oil to substrate). }\end{array}$ & $\mathrm{g} / \mathrm{cm}^{2} ; \mathrm{g} / \mathrm{m}^{2}$ \\
\hline Cohesion & $\begin{array}{l}\text { Attractive forces between molecules of the same type (contributing to } \\
\text { the surface tension of a liquid). }\end{array}$ & $\mathrm{n} / \mathrm{a}$ \\
\hline Effective Porosity & Portion of pore spaces in a substrate that can be occupied by oil. & $\%$ \\
\hline Effective Permeability & $\begin{array}{l}\text { A measure of the flow capability of a fluid (e.g., oil) in the presence of } \\
\text { other (e.g., water and/or gas/air) phases within a medium. }\end{array}$ & $\mathrm{m}^{2} ; \mathrm{cm}^{2}$ \\
\hline Hydraulic Conductivity & A measure of the ease with which water flows through sediments. & $\mathrm{m} /$ day $; \mathrm{cm} / \mathrm{s}$ \\
\hline Loading & Amount of oil deposited on a specific portion of shoreline. & $\begin{array}{l}\mathrm{cm}\left(\text { of oil on surface); } \mathrm{g} / \mathrm{m}^{2} ;\right. \\
\mathrm{L} / \mathrm{m}^{3}\end{array}$ \\
\hline $\begin{array}{l}\text { Maximum Holding Capacity or } \\
\text { Maximum Loading }\end{array}$ & $\begin{array}{l}\text { The maximum quantity (of oil) that can occupy a portion of shoreline } \\
\text { (surface and subsurface). }\end{array}$ & $\begin{array}{l}\mathrm{m}^{3} / \mathrm{m} \text { (of shoreline front) } \\
\mathrm{L} / \mathrm{m}^{2} ; \mathrm{L} / \mathrm{m}^{3}\end{array}$ \\
\hline Penetration & Depth to which oil can infiltrate within a shoreline material. & $\mathrm{m}$ \\
\hline Relative Permeability & $\begin{array}{l}\text { The effective permeability divided by a base permeability (i.e., the } \\
\text { absolute permeability). }\end{array}$ & Ratio or \% \\
\hline Storativity & The volume of fluid released from storage per unit surface area. & $\%$ \\
\hline Transmissivity & $\begin{array}{l}\text { The rate of flow under a unit hydraulic gradient through a unit width of } \\
\text { shoreline of given saturated thickness. }\end{array}$ & $\mathrm{m}^{2} /$ day \\
\hline \multicolumn{3}{|c|}{ 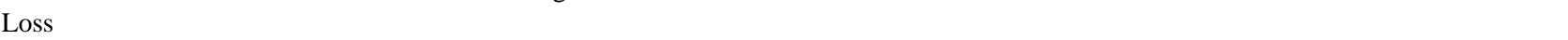 } \\
\hline Acute Phase & $\begin{array}{l}\text { Initial oil removal from shoreline materials due to wave action and } \\
\text { buoyant lifting from tides. }\end{array}$ & Time (days - weeks) \\
\hline Buoyancy & $\begin{array}{l}\text { Upward forces exerted on oil immersed in water, which tend to lift oil } \\
\text { to the water surface. }\end{array}$ & $\mathrm{n} / \mathrm{a}$ \\
\hline Remobilization & Oil translocation through erosion and deposition processes. & $\mathrm{n} / \mathrm{a}$ \\
\hline Residual Capacity/Loading & Oil that is no longer mobile (coating on substrate and trapped in pores). & $\mathrm{L} / \mathrm{m}^{2} ; \mathrm{L} / \mathrm{m}^{3}$ \\
\hline Residual Decay & $\begin{array}{l}\text { Rate of oil loss from the shoreline during the "restoration" or } \\
\text { "weathering" phase. }\end{array}$ & Mass/time; $\%$ \\
\hline Restoration Phase & $\begin{array}{l}\text { Oil removal from shoreline materials after the acute phase (oil } \\
\text { generally no longer mobile). }\end{array}$ & Time (weeks and longer) \\
\hline Retention & Trapping effect of oil within pore spaces. & $\%$ (of porosity); $\mathrm{L} / \mathrm{m}^{3} ; \mathrm{g} / \mathrm{kg}$ \\
\hline Translocation & $\begin{array}{l}\text { Transfer of oil from one medium (i.e., shoreline) to another medium } \\
\text { (i.e., water column) or state (i.e., biodegraded). }\end{array}$ & $\mathrm{n} / \mathrm{a}$ \\
\hline Transition Period & $\begin{array}{l}\text { Period of time between maximum capacity (loading) to residual } \\
\text { loading. }\end{array}$ & Time (days - weeks) \\
\hline Washout & Oil removal processes attributed to wave action and tides. & $\mathrm{n} / \mathrm{a}$ \\
\hline Weathering Period & Period of time after a shoreline has reached residual loading. & Time (weeks and longer) \\
\hline
\end{tabular}


Table 4. Correlation between Viscosity and Penetration Depth for An Average Grain Size of 4.55 mm (from Durgut et al., 2012)

\begin{tabular}{lllllll}
\hline Viscosity $(\mathrm{cP})$ & 1 & 10000 & 20000 & 40000 & 80000 & 160000 \\
\hline Penetration Depth $(\mathrm{cm})$ & 27 & 22 & 11 & 6 & 4 & 3 \\
\hline
\end{tabular}

models (Table 3).

This array of terminology, although understood by engineers, modelers and scientists, may be confusing for individuals not familiar with the subject matter, including decision-makers and the public. To address this, we provide the following simplified explanation of these concepts that influence oil fate and behavior on shorelines: (a) penetration, (b) holding capacity, (c) retention, and (d) the residual capacity.

\subsubsection{Penetration}

Oil that contacts the shoreline can be expected to penetrate into the subsurface if there is sufficient time in which the oil load is in contact with the shoreline and if the oil can effectively flow into the voids (effective permeability). Viscous and emulsified oils may not penetrate sand and granule substrates; thus, if oil is found in the subsurface of a finer-grained shoreline, it is likely due to burial processes (material deposition over stranded oil). As oil effectively penetrates into a shoreline it is mostly, but not entirely, sheltered and removed from surface weathering processes except when the oil is in the zone of normal sediment reworking by wave action and can be remobilized and exposed.

A number of studies have looked at the amount or depth of oil penetration into shoreline materials (Vandermuelen et al., 1988; Humphrey and Harper, 1993; Humphrey et al., 1993; Harper and Kory, 1995; Harper et al., 1995; Durgut et al., 2012; Harper et al., 2018). Penetration is a function of effective porosity, which is a percentage of the total porosity of the shoreline given that some pore spaces may not be completely filled (water) and /or not be connected to each other. As fluid viscosity increases, the effective porosity decreases, thus higher viscosity oils penetrate less into a given grain size substrate relative to lower viscosity oils.

Penetration is also dependent on the water saturation of the beach sediment; hence, lower intertidal sediments, which typically retain some of the ebb tide outflow or backshore groundwater, have a lower potential for oil penetration compared to the middle to supratidal zones. Tidal water levels within the shoreline, and associated pore saturation, vary between low and high tides forming a modified "wedge" in which oil may penetrate into beach sediment (Boufadel et al., 2019). Groundwater runoff through a beach may further limit oil penetration into the subsurface relative to the tidal hydraulic wedge.

Oil loading experiments examining physical and sedimentological parameters that determine penetration of oil into fine sediments have shown that penetration and hydrocarbon concentration varied inversely with mud (silt and clay) content. The occurrence of fine-grain (mud) concentrations as low as $2 \%$ in fine sands greatly reduces oil penetration (Vandermuelen et al., 1988). The same studies also note that penetration and subsurface hydrocarbon concentrations were higher in sediments ti- dally exposed for $57 \%$ or longer of the tidal cycle (upper intertidal) and that submergence for $33 \%$ or longer of the tidal cycle resulted in much lower penetration and oil retention. Maximum oil concentrations reached 30,000 to $40,000 \mathrm{mg} / \mathrm{kg}$ at $62.5 \%$ submergence with no further increases observed up to $100 \%$ submergence.

Repeated tidal cycles can also effectively transport oil to greater depths, as shown in SINTEF tests in which eight tidal cycles revealed an asymptotic relation to the repeat cycles (Durgut et al., 2012). Those studies show that approximately 50\% of the total penetration depth was achieved in the first tidal cycle, another $20 \%$ in the next tidal cycle, $10 \%$ in the next cycle, and eventually no further change after seven to eight cycles.

Durgut et al. (2012) define a relationship of oil penetration depth in coarse sand as:

$Y=0.1349 x^{2}+1.792 x$

where $Y$ is the penetration depth $(\mathrm{cm}), x$ is the mean grain size $(\mathrm{mm})$. The dependency of penetration on oil viscosity is incurporated into Table 4.

Potential oil penetration into a shoreline is dependent on the amount of oil loaded. Durgut et al. (2012) account for all of these factors in the following equation for the effective oil penetration depth:

$D=D_{v} \cdot C_{L} \cdot C_{G}$

where $D_{v}$ is the penetration depth for the oil viscosity range in Table 4 (for $4.55 \mathrm{~mm}$ grain size), $C_{G}$ is the grain size factor $=$ $f_{\text {grain size }}(G) / f_{\text {grainsize }}(4.55 \mathrm{~mm}), C_{L}$ is the loading factor $=f_{\text {loading }}$ (L) / floading $(10 \mathrm{~mm})$.

These penetration depths generally correlate well with those obtained through experimental results (e.g., Harper and Kory, 1995; Harper et al., 1995) (Figure 2).

\subsubsection{Holding Capacity}

The oil holding capacity for a given substrate is a measure of the volume of oil that can occupy the available pore space for a specific portion of the beach. Etkin et al. (2008) describe the oil holding capacity for any given beach as a function of oil viscosity (as the oil is stranded), effective porosity, water table and water content in pore spaces, and beach geometry (tidal prism). A maximum oil holding capacity is nearly equivalent to the pore space of the sediment less the water content. Gundlach (1987) reports that the average volume of oil is $9.8 \%$ for sand beaches and $8.3 \%$ for gravel (pebble-cobble) beaches. Humphrey et al. (1993) describe the maximum holding capacity of a beach as a direct function of its effective porosity, which they note can range from 12 to $46 \%$. Harper et al. (1995) measured minimum porosities ranging from 35 to $40 \%$ after vibration pack- 
ing of coarse sand to very large pebbles, either as well-sorted sediment or mixed sediments for oil penetration tests in columns. Etkin et al. (2008) conclude that perhaps $20 \%$ of the available pore space can be saturated with oil provided that the oil can penetrate the substrate and oil loading is sufficient to "charge" the pore space. Gundlach (1987) synthesize the maximum loading capacity as shown in Table 5. Cheng et al. (2000) list the same holding capacities as Gundlach (1987) with the following differences: $1.75 \mathrm{~m}^{3} / \mathrm{m}$ for sandy beaches and $0.60 \mathrm{~m}^{3} / \mathrm{m}$ for gravel beaches. Unfortunately, there are significant differences between grain sizes within these simple shoreline categories. Gravel represents a wide range grain sizes (2 to $64 \mathrm{~mm}$ ), and have distinct holding capacities. Another shortcoming of these simple relationships is the lack of defining a relationship between holding capacity and oil viscosity.

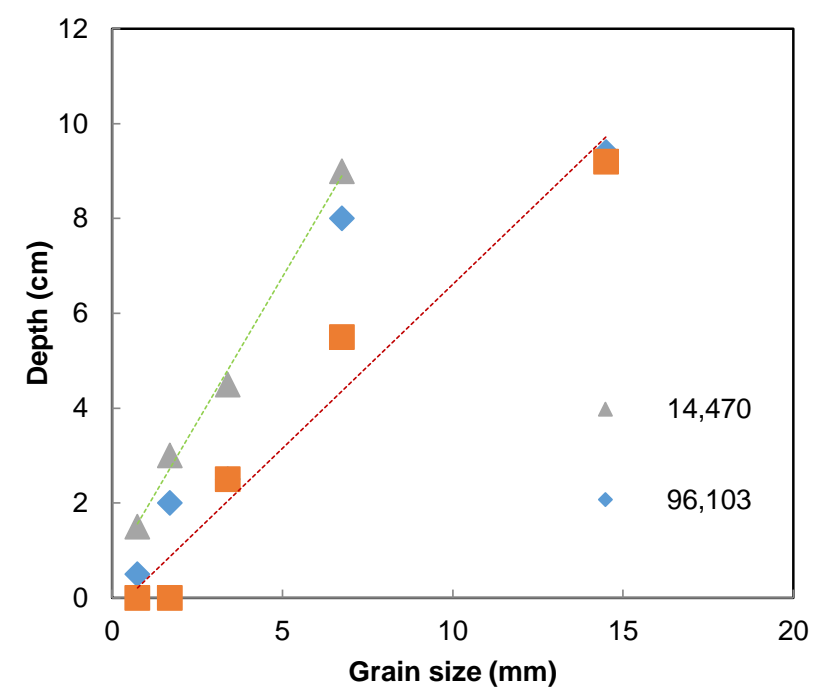

Figure 2. Penetration of Bunker $\mathrm{C}$ oil at three viscosities (cP) as a function of grain size (derived from Harper and Kory, 1995, SOCSEX II).

\subsubsection{Oil Retention}

The rise and fall of tides generally lift oil that can freely flow in pore spaces through buoyancy, providing a likely pathway for oil translocation within shoreline sediments and to adjacent waters. Simple tidal action refloats oil within pore spaces; however, a portion of oil remains trapped within the sediment column due to oil adhesion to particle surfaces and to capillary forces at pore space constrictions. A series of experiments sponsored by Environment Canada (now Environment and Climate Change Canada, ECCC) during the 1990s tested the relationship between oil penetration and retention for various oils in coarse sediments (Subsurface Oil in Coarse Sediment EXperiments - SOCSEX) (Harper and Harvey-Kelly, 1993; Harper et al., 1995). Results from column testing as part of the SOCSEX II series of experiments (Harper and Kory, 1995) showed that oil retention is dependent on oil viscosity and grain size (Table 6 and Figure 3). Tests during SOCSEX II showed that oil retention increased from the initial loading (after one "ebb tide") when columns underwent three "tidal" exchanges and during which floating oil was able to further penetrate into available pore space (Harper and Kory, 1995). Harper et al. (1995) concluded that the maximum oil retention occurs in sediment that is slightly coarser than the penetration-limiting grain size. A missing component in these studies, however, is an assessment of the amount of oil released, or refloated, after each flood cycle. Eventually the buoyant effect of tidal action on oil remaining in pore spaces diminishes markedly.

\subsubsection{Residual Capacity}

The portion of oil coating and adhering to grains, and trapped at throat constrictions within pore spaces, that can be remobilized through the buoyancy process decreases with time. This retained oil is generally referred to as the residual oil (Gundlach, 1987; Humphrey et al., 1993). For any given oil penetration, the amount of oil retained through adhesion and capillary forces is greater for finer-grained sediments due to increased surface area and number of grain-to-grain contacts (Harper et al., 1995).

Humphrey et al. (1993) show a range of 5 to $40 \mathrm{~L} / \mathrm{m}^{3}$ as the residual capacity for light fuel oils (gasoline, diesel) in substrate as a function of grain size (their Figure 4). For coarse sediments and medium crude oils, the residual capacity is noted as $4.5 \mathrm{~L} / \mathrm{m}^{3}$. Experiments in oil retention have been fundamental objectives of multiple ECCC experiments (Harper et al., 1995; Harper and Kory, 1995; Harper et al., 1997; LaForest et al., 2017; Britton and Harper, 2018) and of column tests at SINTEF (Ramstad et al., 2019). As with oil penetration, oil retention is dependent on oil viscosity, adhesion, grain size, and effective porosity, as well as tidal conditions.

\subsection{Phases in Oil Attenuation from Shorelines}

Oil on and within beaches may undergo rapid removal through the physical forces of wave action or slowly attenuate under conditions with little wave action or tidal flushing. Humphrey et al. (1993) recognized three periods during the self-cleaning phases for oiled coarse-grained shorelines based on the Baffin Island Oil Spill (BIOS) field experiments: (1) a first relatively short period of remobilization or "self-cleaning" representing the time during which oil is reduced from that in excess of the shoreline maximum loading capacity to the maximum loading capacity, (2) a relatively longer transition period in which oil is reduced from the maximum loading capacity to a residual capacity, and (3) a long-term period representing continued physical and chemical degradation and weathering in which oil is reduced to levels below the residual capacity.

\subsubsection{Bulk or Mobile Oil Translocation (Buoyancy and Washout)}

The initial bulk removal of oil from a shoreline has been referred to as the acute phase (Ramstad et al., 2019) or as the transition rate from maximum capacity (or high loading) to residual capacity (Humphrey et al., 1993; Humphrey, 1995). This phase can result in the transfer of bulk, mobile oil on surface sediments and in the porous subsurface substrate to the adjacent 


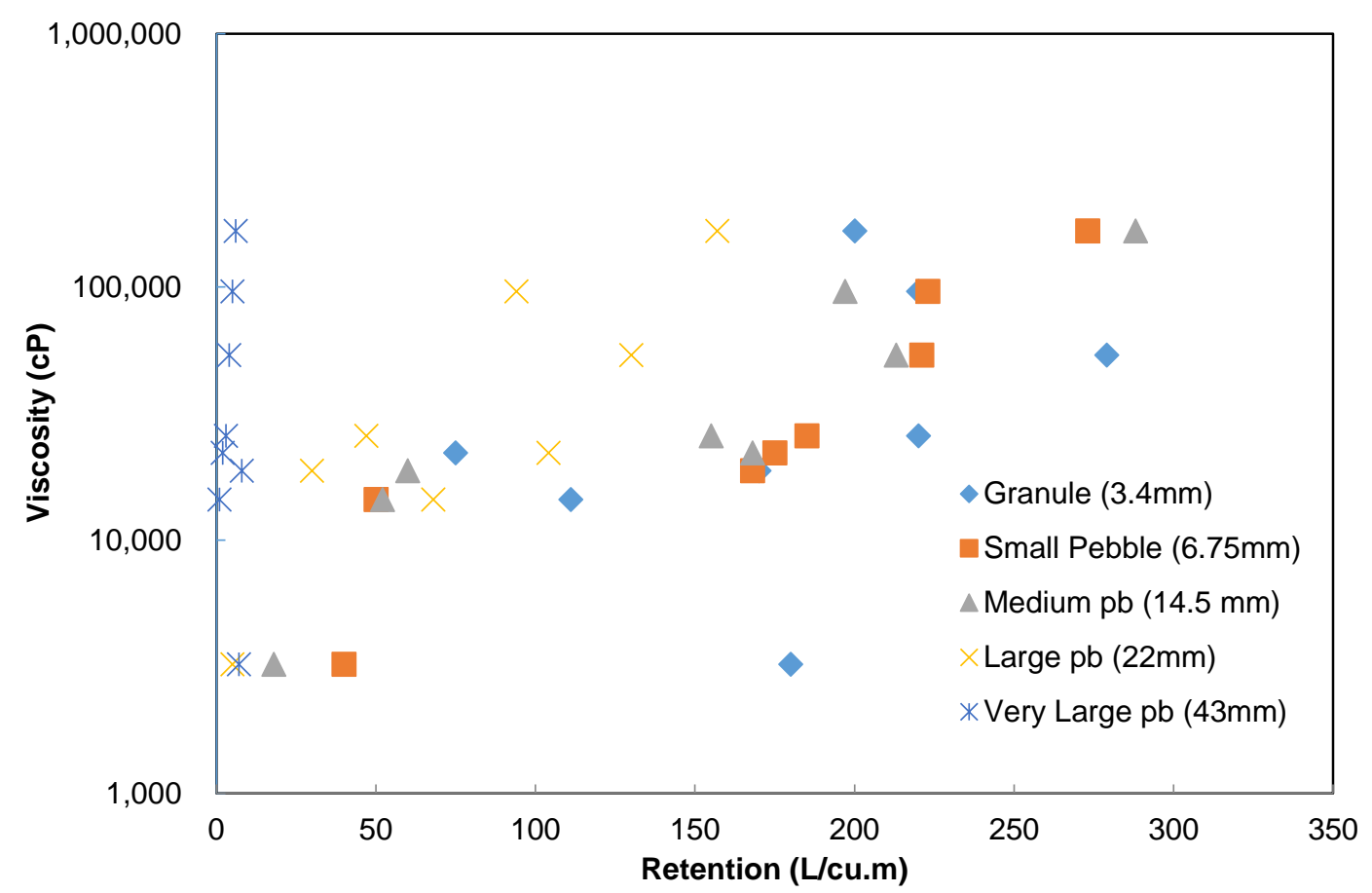

Figure 3. Oil retention as a function of grain sizes and oil viscosity (derived from data in Harper and Kory, 1995).

Table 5. Maximum Oil Loading Capacity for Shorelines (from Gundlach, 1987*)

\begin{tabular}{|c|c|c|c|c|c|}
\hline \multirow[t]{2}{*}{ Shoreline } & \multicolumn{5}{|c|}{ Loading Capacity $\left(\mathrm{m}^{3}\right.$ Per Linear $\mathrm{m}$ of Shoreline) } \\
\hline & Average Surface & Average Subsurface & Overall Average & $\begin{array}{l}\text { Overall Max } \\
(+1 \text { STD. DEV.) }\end{array}$ & $\begin{array}{l}\text { Overall Min } \\
\text { (-1 STD. DEV.) }\end{array}$ \\
\hline Bedrock & 0.01 & - & 0.01 & - & 0 \\
\hline Sand Beach & 2.02 & 0.14 & 2.16 & 1.84 & 4.06 \\
\hline Gravel Beach & 0.50 & 0.18 & 0.68 & 0 & 1.47 \\
\hline Tidal Flat & 0.12 & - & 0.12 & 0.24 & 0 \\
\hline Marsh & 0.30 & - & 0.30 & 0.16 & 0.44 \\
\hline
\end{tabular}

*Assumes a 4 m vertical tide plus $1 \mathrm{~m}$ vertical swash

water column where it may be further diluted or re-strand locally or elsewhere. This phase is ascribed to the initial 1 to 5 days post-oiling (Gundlach, 1987) (Table 7) and is the main component used in oil spill models that focus on floating oil and oil trajectories (see in Discussion, below).

Reed et al. (1995) describe the amount of oil removed from a shoreline segment, $i$, during a time step, $\Delta t$, as:

$$
\Delta m=m_{i}\left(1-\exp \left[-r_{i} \Delta t\right]\right)
$$

where $m_{i}=$ mass of oil on segment $\mathrm{i}$ at beginning of time step, $r_{i}=$ removal rate for the appropriate shoreline type.

Both Gundlach (1987) and Humphrey et al. (1993) describe a first-order decay rate for the removal of oil during the excess oil removal and transition stage as:

$$
[O I L]_{t}=[O I L]_{i n i t} \cdot e^{(-k t)}
$$

where Humphrey et al. $(1993)$ describe $[O I L]_{\text {init }}=$ the residual oil, equivalent to $4.5 \mathrm{~L} / \mathrm{m}^{3}, k=0.2$ (monthly basis) or 0.006 (daily basis) or 0.003 (semi-diurnal tide cycle basis).

Humphrey et al. (1993) note that this rate is subject to a number of factors, among which wave action, oil viscosity and adhesion, are expected to have significant contributions. Gundlach (1987) provides estimated ranges of the decay constant, $k$, for six substrates. These same rates are used in the SINTEF OSCAR model for oil attenuation on shorelines.

\subsubsection{Residual Oil Translocation (Oil-Particulate Aggregates} and Biodegradation)

In an analysis of oil on coarse sediment shorelines, Humphrey (1993) reviewed twelve studies to ascertain oil removal rates from shorelines. Noting that differences found may be attributable to a number of factors, the overall oil decay process from laboratory studies and field observations revealed decay rates, $k_{1}$, of total petroleum hydrocarbon (TPH) in sediments of -0.0005 to -0.0125 for those data with a correlation of 0.7 or better (Humphrey, 1993, Table 1). As discussed in the 
E. Taylor et al. / Journal of Environmental Informatics Letters 5(1) 27-38 (2021)

Table 6. Oil Retained within Different Grain Sizes after Flooding Columns (Derived from Harper and Kory, 1995)*

\begin{tabular}{|c|c|c|c|c|c|c|c|c|c|c|}
\hline \multicolumn{11}{|c|}{ Mean Grain Size Diameter (mm) } \\
\hline 0.75 & 1.7 & 3.4 & 6.75 & 14.5 & 15 & 22 & 43 & & & \\
\hline $\mathrm{CS}$ & VCS & $\mathrm{G}$ & SP & MP & $\mathrm{M}$ & LP & VLP & \multirow{2}{*}{ Oil Type } & \multirow{2}{*}{ Viscosity $(\mathrm{cP})$} & \multirow{2}{*}{ Adhesion (g/sq m) } \\
\hline \multicolumn{8}{|c|}{ Retention (L/cu.m) } & & & \\
\hline \multirow[t]{6}{*}{127} & 116 & 111 & 50 & 52 & & 68 & 5 & Bunker $\mathrm{C}, 0 \%$ at $15^{\circ} \mathrm{C}$ & 14,470 & 91 \\
\hline & & 75 & 175 & 168 & 163 & 104 & 25 & Bunker $\mathrm{C}, 6 \%$ at $15^{\circ} \mathrm{C}$ & 22,135 & 126 \\
\hline & & 220 & 185 & 155 & & 47 & 24 & Bunker $\mathrm{C}, 0 \%$ at $10^{\circ} \mathrm{C}$ & 25,790 & 91 \\
\hline & & 279 & 221 & 213 & & 130 & 51 & Bunker $\mathrm{C}, 0 \%$ at $5^{\circ} \mathrm{C}$ & 53,765 & 91 \\
\hline & 305 & 220 & 223 & 197 & & 94 & 77 & Bunker $\mathrm{C}, 0 \%$ at $2{ }^{\circ} \mathrm{C}$ & 96,103 & 91 \\
\hline & & 200 & 273 & 288 & 185 & 157 & 85 & Bunker $\mathrm{C}, 6 \%$ at $2{ }^{\circ} \mathrm{C}$ & 166,462 & 126 \\
\hline 37 & 128 & 180 & 40 & 18 & 15 & 5 & 0 & IFO, $2.5 \%$ at $15^{\circ} \mathrm{C}$ & 3,232 & 63 \\
\hline 75 & 175 & 170 & 168 & 60 & 40 & 30 & 5 & IFO, $2.5 \%$ at $2{ }^{\circ} \mathrm{C}$ & 18,815 & 63 \\
\hline
\end{tabular}
sand, VCS - very coarse sand, G - granules, SP - small pebbles, MP - medium pebbles, M - marbles, LP - large pebbles, VLP - very large pebbles].

Table 7. Oil Removal Rates by Shoreline Type and Wave Energy (after Gundlach, 1987, Table 3)

\begin{tabular}{|c|c|c|c|c|}
\hline Shoreline & Wave Conditions & $\%$ Removed (1 Day) & $\%$ Removed (5 Days) & Removal Rate $\left(k_{1}\right)$ \\
\hline \multirow[t]{2}{*}{ Bedrock } & Exposed & $60 \sim 63$ & $99 \sim 99.3$ & $0.90 \sim 0.99$ \\
\hline & Sheltered & $5 \sim 10$ & $5 \sim 22$ & $0.01 \sim 0.05$ \\
\hline \multirow[t]{2}{*}{ Eroding Peat Scarps } & Low wave $(<1 \mathrm{~m})$ & $10 \sim 18$ & $49 \sim 63$ & $0.10 \sim 0.20$ \\
\hline & High wave $(>1 \mathrm{~m})$ & $50 \sim 55$ & $97 \sim 98$ & $0.70 \sim 0.80$ \\
\hline \multirow[t]{2}{*}{ Sand Beaches } & $\begin{array}{l}\text { Low wave }(<1 \mathrm{~m}) \\
\text { (beach face) }\end{array}$ & $18 \sim 26$ & $61 \sim 78$ & $0.20 \sim 0.30$ \\
\hline & High wave (> $1 \mathrm{~m}$ ) & $40 \sim 45$ & $92 \sim 95$ & $0.50 \sim 0.60$ \\
\hline \multirow[t]{2}{*}{ Gravel Beaches } & $\begin{array}{l}\text { Low wave }(<1 \mathrm{~m}) \\
\text { (beach face) }\end{array}$ & $10 \sim 18$ & $40 \sim 63$ & $0.10 \sim 0.20$ \\
\hline & High wave (> $1 \mathrm{~m})$ & $33 \sim 40$ & $86 \sim 92$ & $0.40 \sim 0.50$ \\
\hline Tidal Flats & (considered low energy) & $60 \sim 63$ & $99 \sim 99.3$ & $0.90 \sim 0.99$ \\
\hline Marshes & (considered low energy) & $0.1 \sim 1.0$ & $0.5 \sim 5$ & $0.001 \sim 0.01$ \\
\hline
\end{tabular}

same study, Humphrey describes this first order decay rate in terms of half-life as:

Half - Life $($ days $)=\log (2) / k_{1}$

which in his study ranged from approximately 20 days to 750 days, with a mean of 80 days. As Humphrey (1993) points out, approximately $90 \%$ of oil is removed within 3.3 half-lives and a period of ten half-lives results in about $99.9 \%$ of the oil being removed. Boehm et al. (1995) report half-lives for total polyaromatic hydrocarbons (TPAH) in Prince William Sound beaches following the Exxon Valdez oil spill as being between 60 to 75 days for upper and middle intertidal sediments for the first 15 months and 7.4 to 10.6 months (222 to 318 days) for the second year. Mulhare and Therrien (1997) report a first-order decay rate, $k_{1}$, of 0.0025 for No. 2 fuel (diesel) in sand shorelines. The longerterm decay rates cited in these studies likely reflect oil degradation through the formation and dispersion of colloidal oil-particulate aggregates (OcPAs; Boglaienko and Tansel, 2018) and biodegradation.

Decay rates for petroleum hydrocarbons due to biodegradation processes have been the subject of many studies. A study using respiration rates to measure biodegradation of Macondo crude oil in beach sand sediments revealed rates of $0.0038 \mathrm{~d}-1$ for crude oil only and $0.0064 \mathrm{~d}-1$ for crude oil with organic mat- ter added to the substrate (Mortazavi et al., 2013). The same authors indicate that the latter conditions were best represented by two-day curves: $0.0118 \mathrm{~d}-1$ for the first 17 days and $0.0035 \mathrm{~d}-$ 1 afterward. Huettel et al. (2018) found that the half-life of aliphatic and aromatic hydrocarbons from buried Macondo oil in Pensacola sand beaches were 25 and 22 days, respectively. Factors important in the post-treatment reduction of residual oil within these beaches were aerobic degradation promoted by tidal action.

Biodegradation of oil within sediments is affected by available nutrients and oxygen (Atlas and Bragg, 2013; Geng et al., 2015). The BIOMARUN model for oil biodegradation (Geng et al., 2015) reveals faster oil biodegradation in the deeper oiled portion of the upper intertidal sediments relative to shallower depths, mostly as a result of groundwater supplied nutrients. Conversely, biodegradation in the upper portion of the middle intertidal sediments was faster than deeper portions as a result of greater oxygen concentrations from contact with overlying waters. The modeled results show most alkanes and PAH are depleted through biodegradation within 120 days. Bociu et al., (2019) compiled the half-lives of petroleum hydrocarbons (alkanes and PAHs) from numerous studies, showing ranges of 6 to 568 days for alkanes and 33 to 2190 days for PAHs. Their study and that of Collins et al. (2020) also reflect the faster rate of degradation for Deepwater Horizon oil-sand aggregates with- 
in intertidal (periodically inundated) sediments relative to those in the supratidal zone.

In the SOCS model, Humphrey (1995) provides the user with the option for selecting different rate constants (per tide) applicable to the transition phase (transition capacity to residual capacity) and the weathering phase (residual capacity), in which removal through washing (tidal flush) and weathering (OcPA dispersion and biodegradation) are combined during the transition phase. The relative contributions of washing and weathering are not known and only the weathering rate constant is used for estimating attenuation during the residual phase.

In summary, the results from experiments, case studies, and modeling indicate that the persistence of stranded oil is primarily a function of: (a) the oil and sediment properties, and (b) exposure to physical energy (waves) at the shoreline. The following discussion considers the fate of stranded oil with respect to penetration, retention, and attenuation.

\section{Discussion}

\subsection{Relative Importance of Key Variables}

Multiple variables affect how much oil may be stranded on a given shoreline and how long that oil may persist. The wave energy on exposed shorelines can quickly disaggregate (break up, erode) and/or disperse (flush, rinse or wash) stranded oil into adjacent waters. In the absence of wave energy, however, oil translocation is primarily a function of tidal buoyancy and washout, oil-fines interaction, and biodegradation. The location of where oil is stranded on and within the shoreline must be considered given that oil in supratidal locations is less exposed to wave action and tidal flushing than oil within the intertidal zones. Other considerations, such as surface and groundwater runoff and the extent of biofilms on substrates, affect how much oil can be deposited on the shoreline and how well it may adhere to the substrate material. Evans et al. (2017) note the importance of the physical advection of water and sediment to advance oil weathering processes. Studies on the reduction of residual Macondo oil revealed a direct relationship of high weathering rates with high energy shoreline areas and low weathering with low energy conditions (Pendergraft and Rosenheim, 2014; Evans et al., 2017). A conceptual model of the relative contributions of different processes to oil translocation from shorelines is proposed in Figure 4.

\subsection{Models}

Four general models were reviewed that address oil and shoreline interactions (Table 8). Of these four integrated forecast models, only the SOCS model was developed to assess the oil translocation and attenuation pathways of oil off shorelines. The other three models primarily use a shoreline component to inform oil trajectory and fate models on oil contributed (stranded) to shorelines and subsequent release from the shoreline for continued on-water trajectory analyses. The trajectory models typically consider the shoreline oiling component in terms of hours to several days after which no significant oil is released from the shoreline to the adjacent nearshore waters.

\subsection{Uncertainties}

Humphrey et al. (1993) noted the importance of better information for modeling purposes, and specifically highlighted the need to: (1) better understand the effective porosity as a function of grain size, and (2) obtain real measures of the rates of natural removal of oil off shorelines from experiments and/or spills of opportunity. Humphrey (1995) noted that measures of oil viscosity in some of the underlying oil penetration and retention tests (e.g., Harper and Kory, 1995) do not follow conventional patterns (non-Newtonian fluids). Comparable measurements of oil viscosity are needed to better characterize the relation between oil penetration, retention, and effective porosity. As noted in Etkin et al. (2007), much of the information analyzed for aspects of shoreline models, such as maximum oil loading, surface oil load, and oil removal rates, is a by-product that results from research not specifically targeting these objectives. The 2007 review identified that a better understanding of the variables that affect maximum holding capacities was an important information gap; this remains true today.

Another key area for research is to better define the limiting grain size within a shoreline of mixed grain sizes in terms of penetration and retention potential. Although many mixed sediment beaches are "characterized" by the most abundant material (i.e., a pebble-cobble beach), a significant amount of sand in that same beach is effectively the determining factor in oil penetration and retention (possibly the $\mathrm{d} 10$, or $10 \%$ cumulative passing grain size; see Kozeny-Carmen equation for hydraulic conductivity).

A measure of oil release during a series of tidal flushing events would also greatly improve the capability to model this factor in the oil transition phase. Oiled sediment column tests to date have been limited to a maximum of three (SOCS Phase III, Harper and Kory, 1995) to seven (SINTEF, Ramstad et al., 2019) tidal cycles and have not reported the amount of oil lifted (or "buoyed") from the sediment during each tidal flood event. LaForest et al. (2017) and Harper et al., (2018) noted that the amount of oil released following flooding of test columns for four test oils (bunker, two dilbits, and IFO) was time dependent. Submergence for 24 hours resulted in 9 to $24 \%$ of additional oil release compared to the amount released after only 1 hour for the range of oils tested.

The effect of oil-sediment interaction and formation of dispersed OcPAs in both the transition and final weathering phases is an area for further research, as is that of in-situ biodegradetion. Although these two-oil translocation processes may be relatively slower compared to wave cleaning and tidal flushing, they both contribute to oil removal processes from the beginning through to the final stages of attenuation.

\subsection{Goals for the Decision Support Tool}

A refinement of the models reviewed, combined with new data from laboratory and meso-scale experiments, is expected to provide the basis for an "Oiled Shoreline Response Program (SRP) Decision Support Tool". The development of a decision tool or model requires understanding and estimating the natural fate and behavior of oil on shorelines and the consequences of 
Table 8. Features of Existing Oil and Shoreline Interaction Models

\begin{tabular}{|c|c|c|c|c|}
\hline & $\mathrm{SOCS}^{1}$ & SINTEF $^{2}$ & $\mathrm{COZOIL}^{3}$ & OILMAP $^{4}$ \\
\hline Primary Shoreline Focus & $\begin{array}{l}\text { Oil penetration, } \\
\text { retention, and loss }\end{array}$ & $\begin{array}{l}\text { Maximum oil loading, } \\
\text { remobilization }\end{array}$ & Oil retention & $\begin{array}{l}\text { Oil penetration and } \\
\text { remobilization }\end{array}$ \\
\hline \multicolumn{5}{|l|}{ Input Parameters } \\
\hline Oil & Density, viscosity & $\begin{array}{l}\text { Viscosity, oil thickness } \\
\text { on sediment }\end{array}$ & Density, viscosity & Density, viscosity \\
\hline $\begin{array}{l}\text { Substrate Type/ } \\
\text { Sediment Size }\end{array}$ & Grain size & Grain size, storativity & $\begin{array}{l}\text { Shore type (slope and } \\
\text { grain size) }\end{array}$ & $\begin{array}{l}\text { Shore type category by grain } \\
\text { size }\end{array}$ \\
\hline Waves And Tidal Energy & $\begin{array}{l}\text { Wave exposure category, } \\
\text { tides/day }\end{array}$ & Wave height, tidal range & $\mathrm{x}$ & $\mathrm{X}$ \\
\hline Slope & Beach slope or width & $\mathrm{X}$ & $\mathrm{x}$ & $\mathrm{X}$ \\
\hline Width & & $\mathrm{X}$ & $\mathrm{x}$ & $\mathrm{X}$ \\
\hline Other & & Transmissivity & & \\
\hline \multicolumn{5}{|l|}{ Options } \\
\hline & $\begin{array}{l}\text { Beach slope and } \\
\text { grain size by tidal } \\
\text { zone } \\
\text { - Removal rates for } \\
\text { three phases } \\
\text { - Oil concentration } \\
\text { limit in sediment } \\
\text { (max loading) } \\
\text { - Storm enhancement } \\
\text { factor }\end{array}$ & & $\begin{array}{l}\text { Partitioning between } \\
\text { groundwater } \\
\text { (dissolved) and surf } \\
\text { zone (wave action } \\
\text { removal) }\end{array}$ & \\
\hline \multicolumn{5}{|l|}{ Outputs } \\
\hline Volume or Percent & $\begin{array}{l}\text { Oil remaining within } \\
\text { beach segment through } \\
\text { time }\end{array}$ & Oil penetration & $\begin{array}{l}\text { Oil penetration } \\
\text { Oil released (refloated) }\end{array}$ & $\begin{array}{l}\text { Loading (maximum capacity) } \\
\text { Oil released (refloated) }\end{array}$ \\
\hline
\end{tabular}

${ }^{1}$ Humphrey et al., 1992, 1993; Humphrey, 1993, 1996.

${ }^{2}$ Reed and Gundlach, 1989; Reed et al., 1995; Durgut et al., 2012.

${ }^{3}$ Howlett and Jayko, 1998 (unpublished).

${ }^{4}$ RPS, 2016.

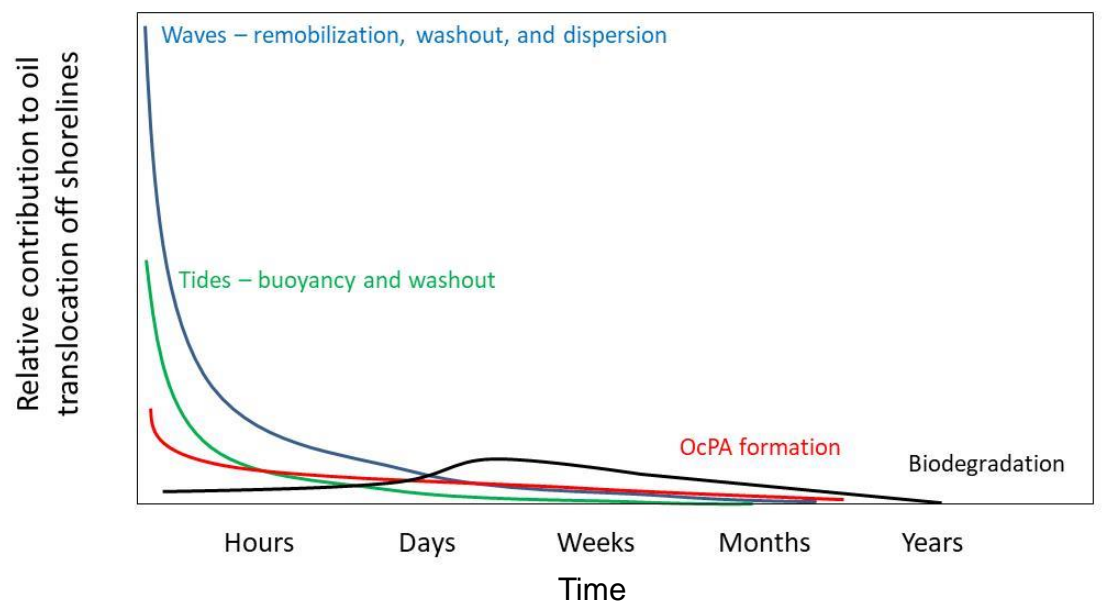

Figure 4. Relative contribution and time scale for principal processes that translocate oil off shorelines.

the wide range of shoreline treatment options. The addition of laboratory results from testing different oils with distinct shoreline grain sizes under extended tidal exchanges with seawater, combined with outcomes of distinct treatment options in these tests, is expected to substantially improve the model. Analyses of oil retention and attenuation over time, in context of grain sizes, oil types, and treatment in the laboratory and meso-scale tests are intended to constrain the variables for the decision tool model. The Decision Support Tool is intended to aid spill scientists, students, environmental resource managers, spill responders, and the public in visualizing the ramifications and consequences of available shoreline treatment options. The tool is being built upon an extensive foundation of the information gained from historical spill cases and from ongoing research. 
Users can delve into the supporting technical papers, large reports, or databases; however, the tool can also be used without the need to fully immerse into the underlying knowledge base. This MPRI SRP Decision Support Tool is intended to be a dynamic, interactive, multi-layered, geographic-based, and seasonal model for shoreline oil spill response decision analyses.

\section{Conclusions}

This review concludes that although there have been studies to improve our understanding of processes controlling the retention, release, and attenuation of oil stranded within shorelines, there has been limited progress on integrated shoreline modeling since the initial studies of Gundlach and Reed (1986) and Humphrey (1994), particularly when compared to the level of effort that has been expended over the decades on other spill technologies (dispersants, herders, de-emulsifiers, fire-resistant boom, etc.). This is a significant imbalance that we aspire to address with the proposed development of a model-driven Oiled Shoreline Response Program (SRP) Decision Support Tool. Although there are models for the various individual physical, chemical, and biological processes, our proposed Decision Support Tool is unique in terms of a predictive integrated model for oil translocation that considers both natural attenuation and active remedial strategies. Improved prediction capabilities for estimating the natural attenuation of oil from shorelines and comparisons with the benefits of select treatment options is important for decision-making during response. Historically, the shoreline component involves the greatest resource commitment, effort, time, and cost elements in most oil spill response operations, and continues far longer than the higher profile on- water phase of a response (Owens and Santner, 2020).

Acknowledgements. The authors kindly acknowledge the suggestions and feedback made to earlier drafts of this manuscript from Blair Humphrey, Alison Craig, Gary Sergy, and Lisa Isaacman. This work was supported in part by the Multi- Partner Research Initiative (MPRI) Pro- ject Oil Translocation under Fisheries and Oceans Canada. The paper does not necessarily reflect the views of the funding entity; no official endorsement should be inferred.

\section{References}

ASCE Task Committee on Modeling of Oil Spills. (1996). State-ofthe-art review of modeling transport and fate of oil spills. Journal of Hydraulic Engineering, 122(11), 594-609. ISSN:0733-9429/96/ 0011-0594-0609

Atlas, R.M. and Bragg, J.R. (2013). Removal of oil from shorelines: biodegradation and bioremediation. Oil in the Environment: Legacies and Lessons of the "Exxon Valdez" Oil Spill", pp 176-196.

Bociu, I., Shin, B., Wells, W.B., Kostka, J.E., Konstantinidis, K.T. and Huettel, M. (2019). Decomposition of sediment-oil-agglomerates in a Gulf of Mexico sandy beach. Scientific Reports, 9(1), 1-13. https://doi.org/10.1038/s41598-019-46301-w

Boehm, P.D., Page, D.S., Gilfillan, E.S., Stubblefield, W.A. and Harner. E.J. (1995). Shoreline ecology program for Prince William Sound, Alaska, following the Exxon Valdez oil spill: Part 2-Chemistry and toxicology. In Exxon Valdez Oil Spill: Fate and Effects in Alaskan Waters, ASTM International. ISBN:0-8031-1896-1

Boglaienko, D. and Tansel, B. (2018). Classification of oil-particle interactions in aqueous environments: aggregate types depending on stare of oil and particle characteristics. Marine Pollution Bulletin, 133, 693-700. https://doi.org/1016/j. marpolbul.2018.06.037

Boufadel, M., Geng, X., An, C.J., Owens, E., Chen, Z., Lee, K., Taylor, E. and Prince, R.C. (2019). A review on the factors affecting the deposition, retention, and biodegradation of oil stranded on beaches and guidelines for designing laboratory experiments. Current Pollution Reports, 5(4), 407-423. https://doi.org/10.1007/S40726-01900129-0

API (2014). Biodegradation and Bio- remediation of Oiled Beaches, A Primer for Planners and Managers. American Petroleum Institute (API), Washington DC, API Technical Report 1147, pp 66.

Britton L. and Harper, J. (2018). Predicting the retention potential of diluted bitumen on marine shorelines: The field implementation of diluted bitumen experiments (BIT_EX). In Proceedings of the Forty-first AMOP Technical Seminar, Environment and Climate Change Canada, Ottawa, ON, pp 254-272.

CEDRE. (2013). Oiled shoreline cleanup manual. Prepared for POSOW (Preparedness for Oil-polluted Shoreline Cleanup and Oiled Wildlife Interventions), REMPEC, Malta, pp 62.

Cheng, N.S., Law, A.W.K. and Findikakis, A.N. (2000). Oil transport in the surf zone. Journal of Hydraulic Engineering, 126(11), 803809. https://doi.org/10.1061/(ASCE)0733-9429(2000)126:11803

Collins, A.W., Elango, V., Curtis, D., Rodrigue, M. and Pardue, J.H. (2020). Biogeochemical controls on biodegradation of buried oil along a coastal headland beach. Marine Pollution Bulletin, 154, 111051. https://doi.org/10.1016/j.marpolbul.2020.111051

De Dominicis, M., Pinardi, N., Zodiatis, G. and Lardner, R. (2013). MEDSLIK-II, a Lagrangian marine surface oil spill model for shortterm forecasting-Part 1: Theory. Geoscientific Model Development, 6(6), 1851-1869. https://doi.org/10.5194/gmd-6-1851-2013

Durgut, I., Rønningen, P., Øksenvåg, J.H.C. and Reed, M. (2012). Advances in shoreline modeling enabled by experimental data. In Proceedings of the 35th AMOP Technical Seminar, Environment Canada, Ottawa ON, pp 689-706.

ECCC (2016). A Field Guide to Oil Spill Response on Marine Shorelines. Prepared and provided by Polaris Applied Sciences, and S3 Environmental Inc., for Environment and Climate Change Canada, Ottawa ON, pp 223.

Etkin, D.S., French-McCay, D. and Michel, J. (2007). Review of the State-of-the-Art on Modeling Interactions between Spilled Oil and Shorelines for the Development of Algorithms for Oil Spill Risk Analysis Modeling. US Department of the Interior Minerals Management Services \& Environmental Research Consulting, Cortlandt Manor, NY, pp 157.

Etkin D.S., Michel, J., McCay, D.F., Boufadel, M. and Li, H. (2008) Integrating state-of-the-art shoreline interaction knowledge into spill modeling. In International Oil Spill Conference, 2008(1), 915922. https://doi.org/10.7901/2169-3358-2008-1-915

Evans, M., Liu, J., Bacosa, H., Rosenheim, B.E. and Liu, Z. (2017). Petroleum hydrocarbon persistence following the Deepwater Horizon oil spill as a function of shoreline energy. Marine Pollution Bulletin, 115(1-2), 47-56. https://doi.org/10.1016/j.marpolbul.2016. 11.022

Geng, X., Boufadel, M.C., Lee, K., Abrams, S. and Suidan, M. (2015). Biodegradation of subsurface oil in a tidally influenced sand beach: Impact of hydraulics and interaction with pore water chemistry. Water Resource Research, 51(5), 3193-3218. https://doi.org/10. 1002/2014WR016870

Ghattas, A.K., Fischer, F., Wick, A. and Ternes, T.A. (2017). Anaerobic biodegradation of (emerging) organic contaminants in the aquatic environment. Water Research, 116, 268-295. https://doi.org/ 10.1016/j.watres.2017.02.001

Gundlach, E.R. (1987). Oil-holding capacities and removal coefficients for different shoreline types to computer simulate spills in coastal waters. In International Oil Spill Conference, 1987(1), 451457. https://doi.org/10.7901/2169-3358-1987-1-451

Gundlach, E.R. and Reed, M. (1986). Quantification of oil deposition 
and removal rates for a shoreline/oil spill interaction model. In Proceedings of Arctic and Marine Oilspill Program (AMOP) Technical Seminar, pp 65-76.

Harper, J.R. and Harvey-Kelly, F. (1993). Subsurface oil retention in coarse sediment beaches. Report series No. EE-147, 31.

Harper, J.R. and Kory, M. (1995). Stranded Oil in Coarse Sediment Experiments (SOCSEX II). Report series No. EE-147, 31.

Harper, J.R., Laforest, S. and Sergy, G. (2015). Field investigations of intertidal sediment permeability related to oil retention on British Columbia shorelines. In Proceedings of the 38th Arctic and Marine Oilspill Program (AMOP) Technical Seminar, Vancouver, BC, 631648.

Harper, J., Sergy, G. and Kory, M. (1997). Orimulsion® sediment interaction scoping experiments. In Proc. 20th Arctic and Marine Oil spill Program (AMOP) Technical Seminar, Environment Canada, Ottawa, ON, pp 1121-1132.

Harper, J., Sergy, G. and Sagayama, T. (1995). Subsurface oil in coarse sediments experiments (SOCSEX II). In Arctic and Marine Oilspill Program Technical Seminar, pp 867-886.

Harper, J., Sergy, G., Britton, L., Laforest, S. and Lambert, P. (2018) Diluted Bitumen Sediment Interaction Experiments (Bit_EX): Diluted Bitumen Penetration and Retention on Shorelines, In Proceedings of the Forty-first AMOP Technical Seminar, Environment and Climate Change Canada, Ottawa, ON, pp 273-295.

Huettel, M., Overholt, W.A., Kostka, J.E., Hagan, C., Kaba, J., Wells, W.B. and Dudley, S. (2018). Degradation of Deepwater Horizon oil buried in a Florida beach influenced by tidal pumping. Marine Pollution Bulletin, 126, 488-500. https://doi.org/10.1016/j.marpol bul.2017.10.061

Humphrey, B. (1993). Persistence of oil in subtidal sediments. In Proceedings of the Seventeenth Arctic and Marine Oilspill Program Technical Seminar. Environment Canada, Ottawa ON, pp 75-83.

Humphrey, B. (1994). Stranded Oil in Coarse Sediments (SOCS) Model. Report Series No. EE-146. 27.

Humphrey, B. (1995). Hindcasting the persistence of oil on shorelines with the SOCS model. In Proceedings of the Eighteenth Arctic and Marine Oilspill Program Technical Seminar, Environment Canada, Ottawa ON, pp 685-688.

Humphrey, B. and Harper, J. (1993). Coarse sediment oil persistence: laboratory studies and model. In Proceedings of the Sixteenth Arctic and Marine Oil spill Program (AMOP) Technical Seminar, Environment Canada, Ottawa, ON, pp 1-10.

Humphrey, B., Owens, E.H. and Patrick, G. (1992). Coarse Sediment and Oil Database and Fate Model. Environmental Emergencies Manuscript Report Number EE-139, Environment Canada, Ottawa, ON, pp 43.

Humphrey, B., Owens, E.H. and Sergy, G. (1993). Development of a stranded oil in coarse sediment (SOCS) model. In International Oil Spill Conference, 1993(1), 575-582. https://doi.org/10.7901/21693358-1993-1-575

IMO. (2005). Manual on Oil Pollution, Section IV- Combating oil spills. International Maritime Organization, London, UK, pp 212.

IPIECA-IOGP. (2015). A guide to shoreline clean-up techniques. Good practice guidelines for incident management and emergency response personnel. IOGP Report 521, London, UK, pp 65.

LaForest, S., Lambert, P., Harper, J. and Sergy, G. (2017). Meso-scale studies on the penetration and retention of diluted bitumen in different types of shorelines, Northern British Columbia, Canada. In International Oil Spill Conference Proceedings, 2017(1), 22682285. https://doi.org/10.7901/2169-3358-2017.1.2268

Lee, K., Boufadel, M., Chen, B., Foght, J., Hodson, P., Swanson, S. and Venosa, A. (2015). Expert Panel Report on the Behaviour and Environmental Impacts of Crude Oil Released into Aqueous Environments. Royal Society of Canada, Ottawa, ON. ISBN: 9781-928140-02-3

Mortazavi, B., Horel, A., Beazley, M.J. and Sobecky, P.A. (2013). Intrinsic rates of petroleum hydrocarbon biodegradation in Gulf of
Mexico intertidal sandy sediments and its enhancement by organic substrates. Journal of Hazardous Materials, 537-544. https://doi. org/10.1016/j.jhazmat.2012.10.038

Mulhare, M.J. and Therrien, P.J. (1997). Persistence of oil in beach sand following a catastrophic release of No. 2 fuel oil. In International Oil Spill Conference, 1997(1), 409- 413. https://doi.org/10. 7901/2169-3358-1997-1-409

NOAA. (2003). Shoreline Assessment Manual. 4th Edition. U.S. Dept. of Commerce. Seattle, WA: Emergency Response Division, Office of Response and Restoration, National Oceanic and Atmospheric Administration, pp 73

NRC. (2003). Oil in the Sea III: Inputs, Fates and Effects. National Academies Press (US). https://doi.org/10.17226/10388

Owens, E.H., Robson, W. and Humphrey, B. (1986). Data on the character of asphalt pavements. In Proceedings of the 9th Annual Arctic and Marine Oil Spill Program (AMOP) Technical Seminar, Edmonton, Alberta. Ottawa, Canada: Environment Canada, pp 117.

Owens, E.H. and Santner, R. (2020). Integration of a Shoreline Response Program (SRP) and SCAT. Proceedings of the International Oil Spill Conference.

Owens, E.H., Taylor, E. and Humphrey, B. (2008). The persistence and character of stranded oil on coarse-sediment beaches. Marine Pollution Bulletin, 56(1), 14-26. https://doi.org/10.1016/j.marpolb ul.2007.08.020

Owens, E., Taylor, E., An, C.J., Chen, Z., Danner, G., Gmur, S. and Lee, K. (2021). A Shoreline Response Program (SRP) Decision Support Tool based on the Geographic Variability in Attenuation and Weathering of Oil Stranded in Canadian Marine Coastal Environments. In Proceedings of the International Oil Spill Conference.

Pendergraft, M.A. and Rosenheim, B.E. (2014). Varying relative degradation rates of oil in different forms and environments revealed by ramped pyrolysis. Environmental Science \& Technology, 48(18), 10966-10974. https://doi.org/10.1021/es501354

Pope, G.A., Gordon, K.D. and Bragg, J.R. (2013). Understanding subsurface contamination using conceptual and mathematical models. Oil in the Environment: Legacies and Lessons of the Exxon Valdez Oil Spill, 144-175.

Prince, R.C., Butler, J.D. and Redman, A.D. (2017). The rate of crude oil biodegradation in the sea. Environmental science \& technology, 51(3), 1278-1284. https://doi.org/10.1021/acs.est.6b03207

Ramstad, S., Oksenvag, J.H.C., Oltedal, T.A., Johansen, B. and Daling, P.S. (2019). Fate and behaviour of oil in acute phase-meso scale shoreline basin studies. Trondheim, Norway: SINTEF, Report nr OC2019 A-038.

Ramstad, S., Oksenvag, J.H.C., Johansen, B. and Oltedal, T.A. (2019). Fate and behaviour of oil on shoreline in restoration phase-meso scale basin studies. Trondheim, Norway: SINTEF, Report nr OC2019 A-039.

Reed, M., Gundlach, E. and Kana, T. (1989). A coastal zone oil spill model: development and sensitivity studies, Oil and Chemical Pollution, 5(6), 411-449. https://doi.org/10.1016/S0269-8579(89) 80019-X

Reed, M., French, D., Rines, H. and Rye, H. (1995). A threedimensional oil and chemical spill model for environmental impact assessment. In International Oil Spill Conference: Conference, 1995(1), 61-66. https://doi.org/10.7901/2169-3358-1995-1-61

RPS (2016). OILMAP Version 7 Technical User's Manual.

Samaras, A.G., De Dominicis, M., Archetti, R., Lamberti, A. and Pinardi, N. (2014). Towards improving the representation of beaching in oil spill models: A case study. Marine Pollution Bulletin, 88(1-2), 91-101. https://doi.org/10.1016/j.marpolbul.2014. 09.019

Vandermeulen, J.H., Harper, J.R. and Humphrey, B. (1988). Environmental factors influencing oil penetration and persistence in fine sediment tidal flats. Oil and Chemical Pollution, 4(3), 155-177. https://doi.org/10.1016/S0269-8579(88)80018-2 